\title{
\#USES
}

science for a changing world

Prepared in cooperation with the U.S. Fish and Wildlife Service, Bureau of Land Management, and U.S. Forest Service

Effects of Barred OwI (Strix varia) Removal on Population Demography of Northern Spotted Owls (Strix occidentalis caurina)

in Mashington and Oregon-2019 Amnial Report

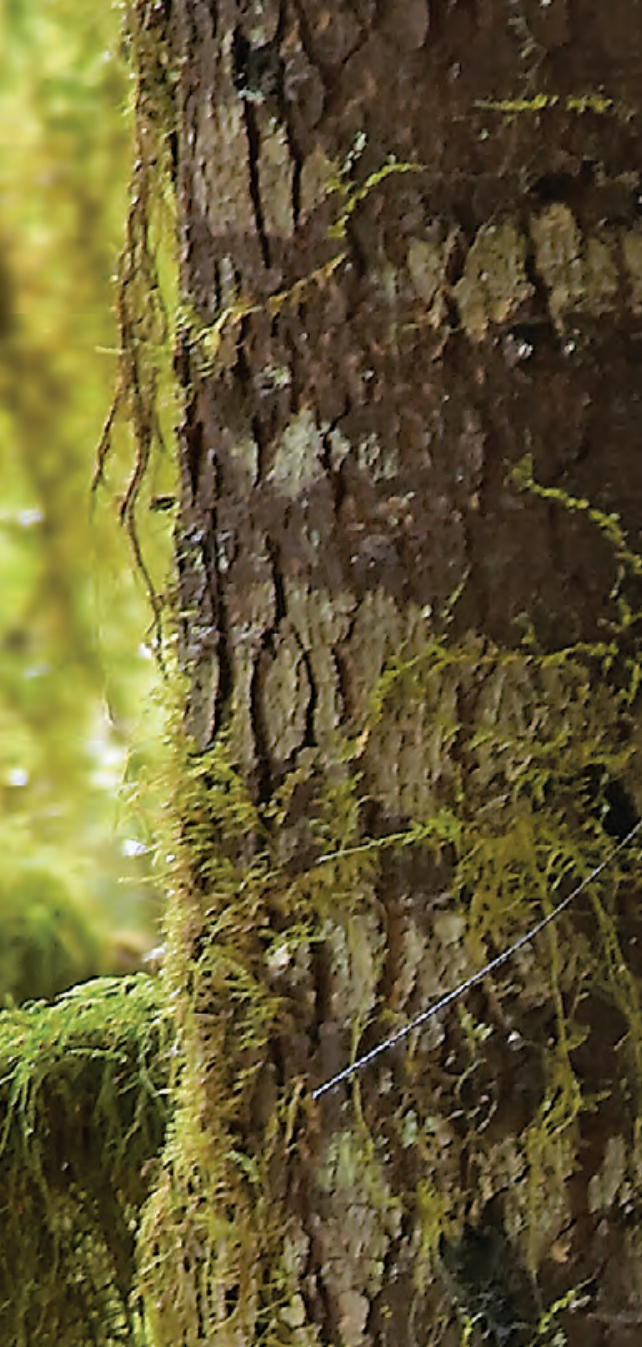

Open-File Report 2020-1089
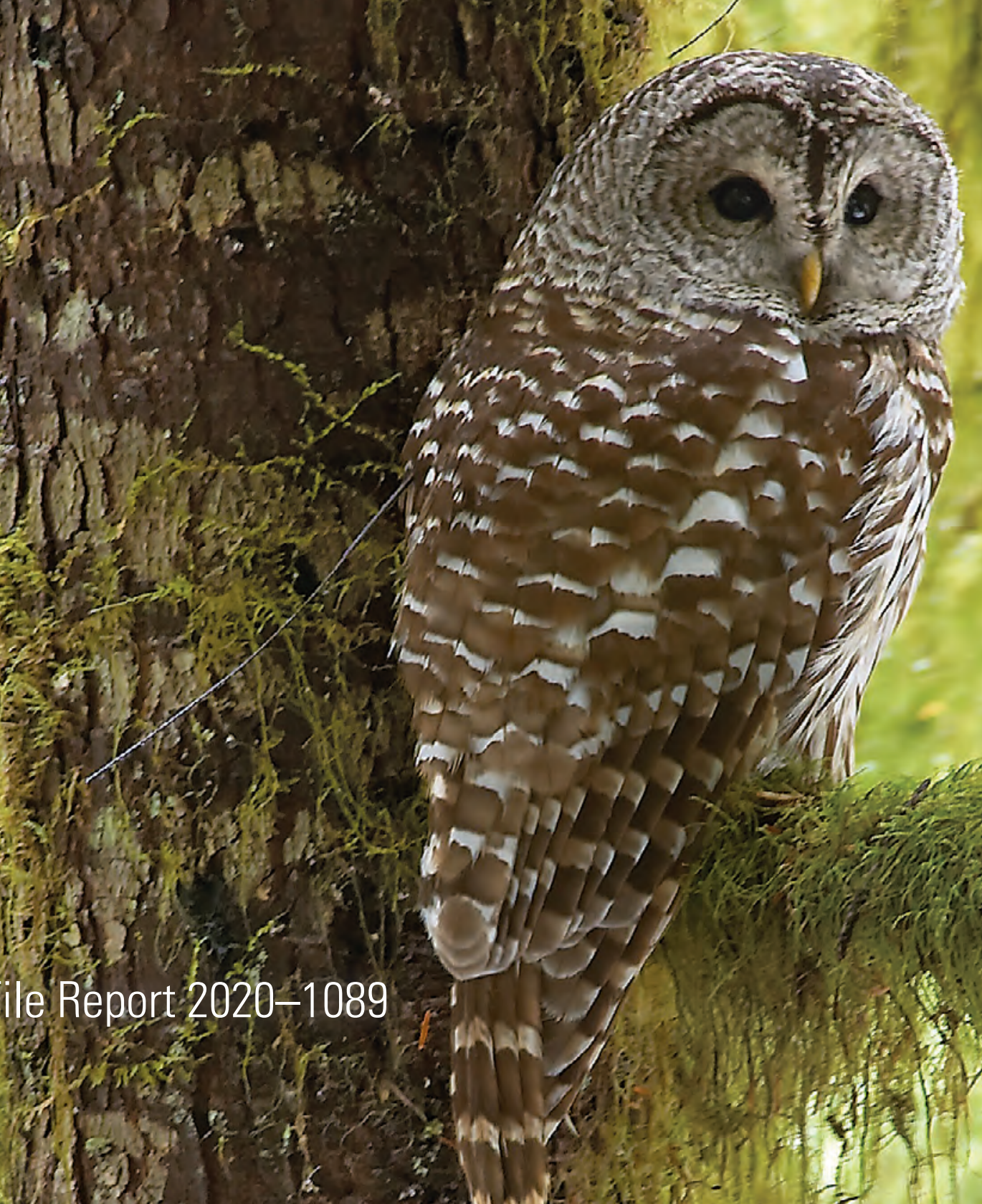

U.S. Departiment of the Interior U.S. Geological Survey

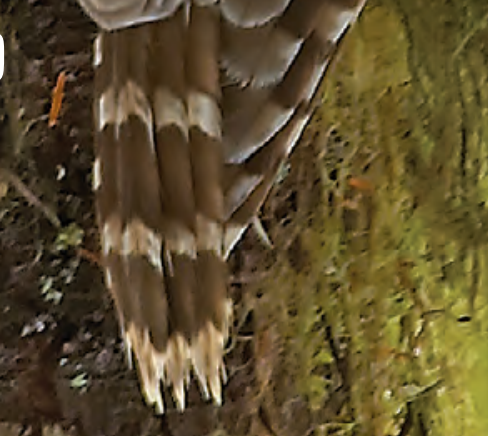


Cover: Photograph of a female barred owl (Strix varia) in the Oregon Coast Range. Photograph copyright by Patrick Kolar, Oregon State University, 2006. Used with permission. 


\section{Effects of Barred Owl (Strix varia) Removal on Population Demography of Northern Spotted Owls (Strix occidentalis caurina) in Washington and Oregon-2019 Annual Report}

By J. David Wiens, Katie M. Dugger, Damon B. Lesmeister, Krista E. Dilione, and David C. Simon

Prepared in cooperation with the U.S. Fish and Wildlife Service, Bureau of Land Management, and U.S. Forest Service

Open-File Report 2020-1089 


\title{
U.S. Department of the Interior \\ DAVID BERNHARDT, Secretary
}

\author{
U.S. Geological Survey \\ James F. Reilly II, Director
}

U.S. Geological Survey, Reston, Virginia: 2020

For more information on the USGS—-the Federal source for science about the Earth, its natural and living resources, natural hazards, and the environment-visit https://www.usgs.gov/ or call 1-888-ASK-USGS (1-888-275-8747).

For an overview of USGS information products, including maps, imagery, and publications, visit https:/store.usgs.gov.

Any use of trade, firm, or product names is for descriptive purposes only and does not imply endorsement by the U.S. Government.

Although this information product, for the most part, is in the public domain, it also may contain copyrighted materials as noted in the text. Permission to reproduce copyrighted items must be secured from the copyright owner.

Suggested citation:

Wiens, J.D., Dugger, K.M., Lesmeister, D.B., Dilione, K.E., and Simon, D.C., 2020, Effects of barred owl (Strix varia) removal on population demography of northern spotted owls (Strix occidentalis caurina) in Washington and Oregon-2019 annual report: U.S. Geological Survey Open-File Report 2020-1089, 19 p., https://doi.org/10.3133/ofr20201089.

ISSN 2331-1258 (online) 


\section{Contents}

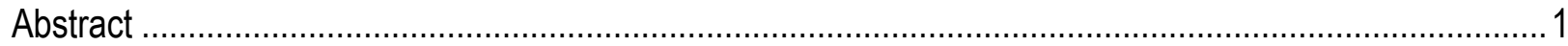

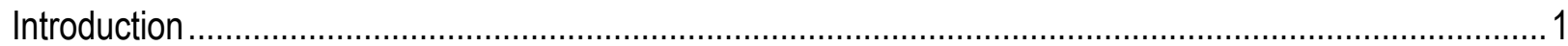

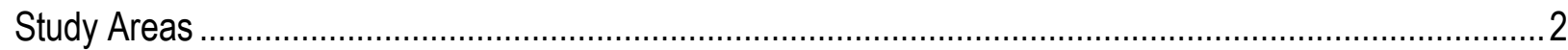

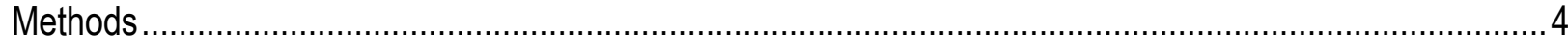

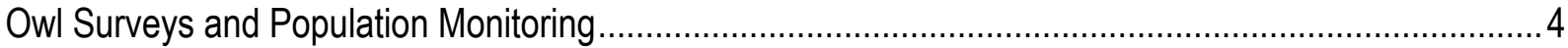

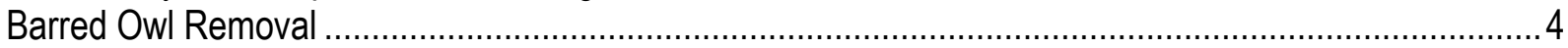

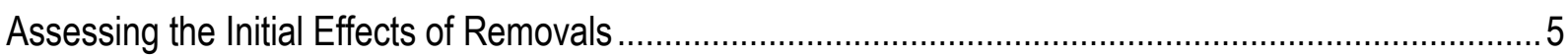

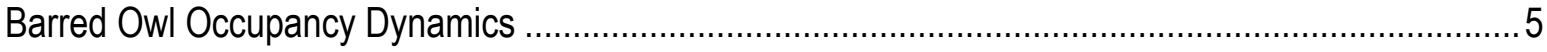

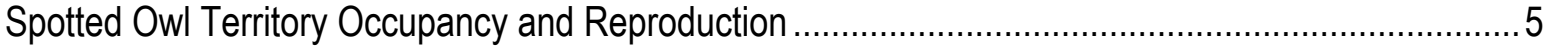

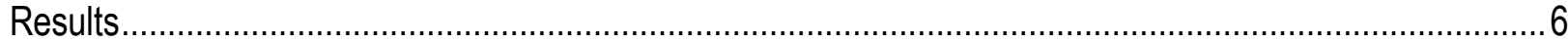

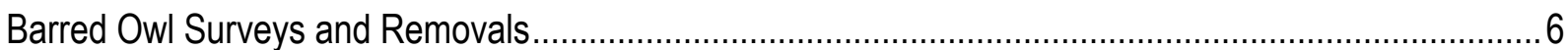

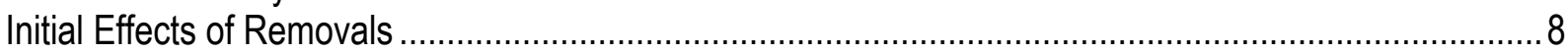

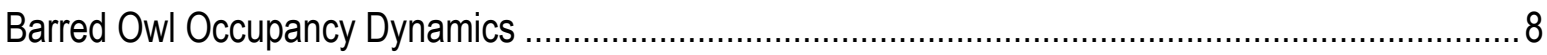

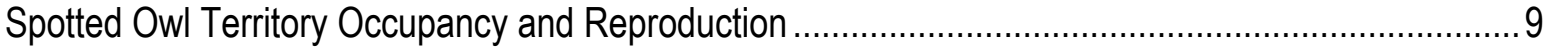

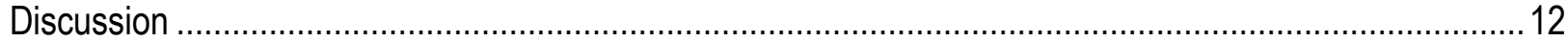

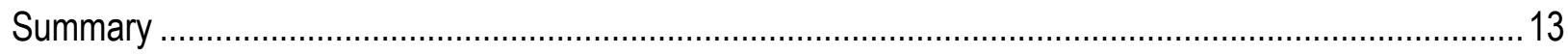

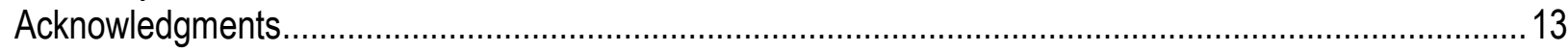

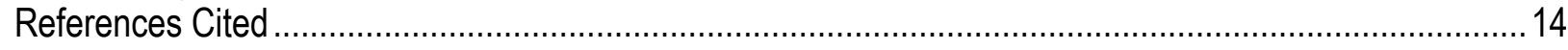

Appendix 1. Disposition of Barred Owl Specimens ............................................................................ 17

Appendix 2. Multi-Season Occupancy Models Used to Characterize Occupancy Dynamics of

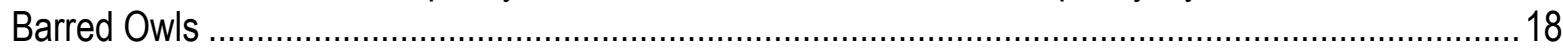

Appendix 3. Post-Removal Extinction and Colonization Rates of Barred Owls ....................................19

\section{Figures}

1. Locations of treatment (barred owls removed) and control (no removal) portions of three study areas in Washington and Oregon used to characterize the effect of barred owl removal on population dynamics of northern spotted owls

2. Average number of barred owls detected per $5-\mathrm{km}^{2}$ hexagon in control (barred owls not removed) and treatment (barred owls removed) portions of three study areas before and after barred owls were removed in Washington and Oregon, 2015-19

3. Numbers of barred owls removed by season in three experimental study areas in Washington and Oregon, 2015-19

4. Variation among study areas and sites in numbers of barred owls removed during $2015-19 \ldots \ldots \ldots \ldots . . . .7$

5. Model-averaged estimates of landscape occupancy by territorial pairs of barred owls in control (barred owls not removed) compared to treatment (barred owls removed) portions of three study areas in Washington and Oregon, 2015-19

6. Long-term (2002-19) annual trends in number of individual (resident) northern spotted owls detected, and total number of young fledged at control (barred owls not removed) and treatment (barred owls removed) portions of three experimental study areas in Washington and Oregon. 


\section{Tables}

1. Study areas, years of removal effort, and samples sizes used to estimate the effects of barred owl removal on population dynamics of northern spotted owls in Washington and Oregon.

2. Model-averaged estimates of expected occupancy by territorial pairs of barred owls, with unconditional standard errors and lower and upper confidence limits, before and after removals in three experimental study areas in Washington and Oregon, 2015-19

3. Annual estimates of territory occupancy by pairs of northern spotted owls in control (barred owls not removed) and treatment (barred owls removed) portions of three study areas in Washington and Oregon, 2015-18.

4. Annual estimates of reproduction of northern spotted owls in control (barred owls not removed) versus treatment (barred owls removed) portions of three study areas in Washington and Oregon, 2015-18

\section{Conversion Factors}

International System of Units to U.S. customary units

\begin{tabular}{lll}
\hline Multiply & By & To obtain \\
\hline meter $(\mathrm{m})$ & Length & \\
\hline & 3.281 & foot $(\mathrm{ft})$ \\
\hline square kilometer $\left(\mathrm{km}^{2}\right)$ & Area & \\
\hline
\end{tabular}




\title{
Effects of Barred Owl (Strix varia) Removal on Population Demography of Northern Spotted Owls (Strix occidentalis caurina) in Washington and Oregon-2019 Annual Report
}

\author{
By J. David Wiens ${ }^{1}$, Katie M. Dugger ${ }^{2}$, Damon B. Lesmeister ${ }^{3}$, Krista E. Dilione ${ }^{1}$, and David C. Simon ${ }^{1}$
}

\begin{abstract}
Strix occidentalis caurina (northern spotted owl; hereinafter referred to as spotted owl) have rapidly declined throughout the subspecies' geographic range. Competition with invading Strix varia (barred owl) has been identified as an immediate cause of those declines. A pilot study in California showed that removal of barred owls coupled with conservation of suitable habitat conditions can slow or even reverse population declines of spotted owls. It is unknown, however, whether similar results can be obtained in areas with different forest conditions, greater densities of barred owls, and fewer remaining spotted owls. We used a before-after-control-impact (BACI) experimental design on three study areas with long-term demographic information on spotted owls to determine if removal of barred owls can improve population trends of spotted owls. This report summarizes research accomplishments and initial results from the first 4.5 years (from March 2015 to August 2019) of implementing barred owl removal experiments in Washington and Oregon.
\end{abstract}

\section{Introduction}

Over the past century Strix varia (barred owls) have expanded their geographic range west from eastern North America, and their newly expanded range now completely overlaps that of the federally threatened S. occidentalis caurina (northern spotted owl). Evidence indicates that competition with invading barred owls has contributed greatly to declines in spotted owl populations (Wiens and others, 2014; Dugger and others, 2016; Yackulic and others, 2019). A pilot study in coastal California demonstrated that removal of barred owls in combination with conservation of suitable forest conditions can slow or even reverse the rate of population decline in spotted owls (Diller and others, 2014, 2016). It remains unknown, however, whether similar results can be obtained in areas with different forest types, greater densities of barred owls, and fewer remaining spotted owls.

In 2015 we initiated a comprehensive before-after-control-impact (BACI) experiment to determine the demographic response of spotted owls to localized removals of barred owls (Wiens and others, 2019). The removal experiment was based on three long-term demographic study areas for spotted owls in Washington and Oregon. The goal of the experiment is to provide a definitive test of whether competitive interactions with barred owls cause population declines of spotted owls, and if so,

\footnotetext{
${ }^{1}$ U.S. Geological Survey, Forest and Rangeland Ecosystem Science Center.

${ }^{2}$ U.S. Geological Survey, Oregon Cooperative Fish and Wildlife Research Unit, Oregon State University.

${ }^{3}$ U.S. Forest Service, Pacific Northwest Research Station.
} 
whether removal of barred owls is an effective tool to consider in long-term management of the two owl species (Johnson and others, 2008; U.S. Fish and Wildlife Service, 2013). Specific objectives of the study are to:

1. Determine the effect of removal of barred owls on vital rates and population trend of spotted owls; and

2. Estimate changes in the occurrence and distribution of barred owls to assess the effectiveness of removals in reducing populations of barred owls.

The purpose of this report is to provide a summary of preliminary results from the first 4.5 years (from March 2015 to August 2019) of removal experiments implemented in Oregon and Washington. The results are considered preliminary, pending final analyses and completion of the study.

\section{Study Areas}

The barred owl removal experiment was spatially replicated in four study areas, each with longterm (1990-2019) data on population demography of spotted owls. This report focuses on initial results from three of these study areas: Cle Elum (Washington), Coast Range (Oregon), and KlamathUnion/Myrtle (Klamath-UM, Oregon, table 1; fig. 1). Experimental study areas were selected based on many considerations, including availability of pre-treatment demographic data on spotted owls, land ownership, and the need to identify the effect of barred owls on spotted owls across a broad range of forest conditions co-occupied by the two owl species (see U.S. Fish and Wildlife Service, 2013 for details on selection of study areas). Each study area was divided into two or more similar areas where barred owls were either removed (treatment areas) or not removed (control areas). The study areas are composed of mostly Federal lands, but fieldwork also occurred on adjacent State, Tribal, and private lands with written permission from the landowner.

Table 1. Study areas, years of removal effort, and samples sizes used to estimate the effects of barred owl removal on population dynamics of northern spotted owls in Washington and Oregon.

[Number of spotted owl territories: Historically occupied territories surveyed for northern spotted owls annually during 2002-19. Number of spotted owls banded: Number of individually color-marked spotted owls used to estimate demographic rates. Number of barred owl sites: Hexagonal plots used to survey barred owls. $\mathrm{km}^{2}$, square kilometer; --, no data]

\begin{tabular}{|c|c|c|c|c|c|}
\hline \multirow[b]{2}{*}{ Treatment level } & \multirow[b]{2}{*}{$\begin{array}{c}\text { Removal start } \\
\text { year }\end{array}$} & \multirow[b]{2}{*}{$\begin{array}{c}\text { Total area } \\
\left(\mathrm{km}^{2}\right)\end{array}$} & \multicolumn{3}{|c|}{ Number of: } \\
\hline & & & $\begin{array}{l}\text { Historical spotted } \\
\text { owl territories }\end{array}$ & $\begin{array}{l}\text { Spotted owls } \\
\text { banded, } \\
2002-2019\end{array}$ & $\begin{array}{l}\text { Barred owl } \\
\text { sites } \\
\left(5 \mathrm{~km}^{2}\right. \\
\text { hexagons })\end{array}$ \\
\hline \multicolumn{6}{|c|}{ Cle Elum, Washington } \\
\hline Control & -- & 670 & 31 & 50 & 109 \\
\hline Treatment & 2015 & 604 & 45 & 52 & 112 \\
\hline \multicolumn{6}{|c|}{ Coast Range, Oregon } \\
\hline Control & -- & 1,015 & 58 & 152 & 178 \\
\hline Treatment & 2015 & 582 & 45 & 84 & 102 \\
\hline \multicolumn{6}{|c|}{ Klamath-UM, Oregon } \\
\hline Control & -- & 698 & 78 & 238 & 122 \\
\hline Treatment & 2016 & 783 & 84 & 242 & 142 \\
\hline
\end{tabular}




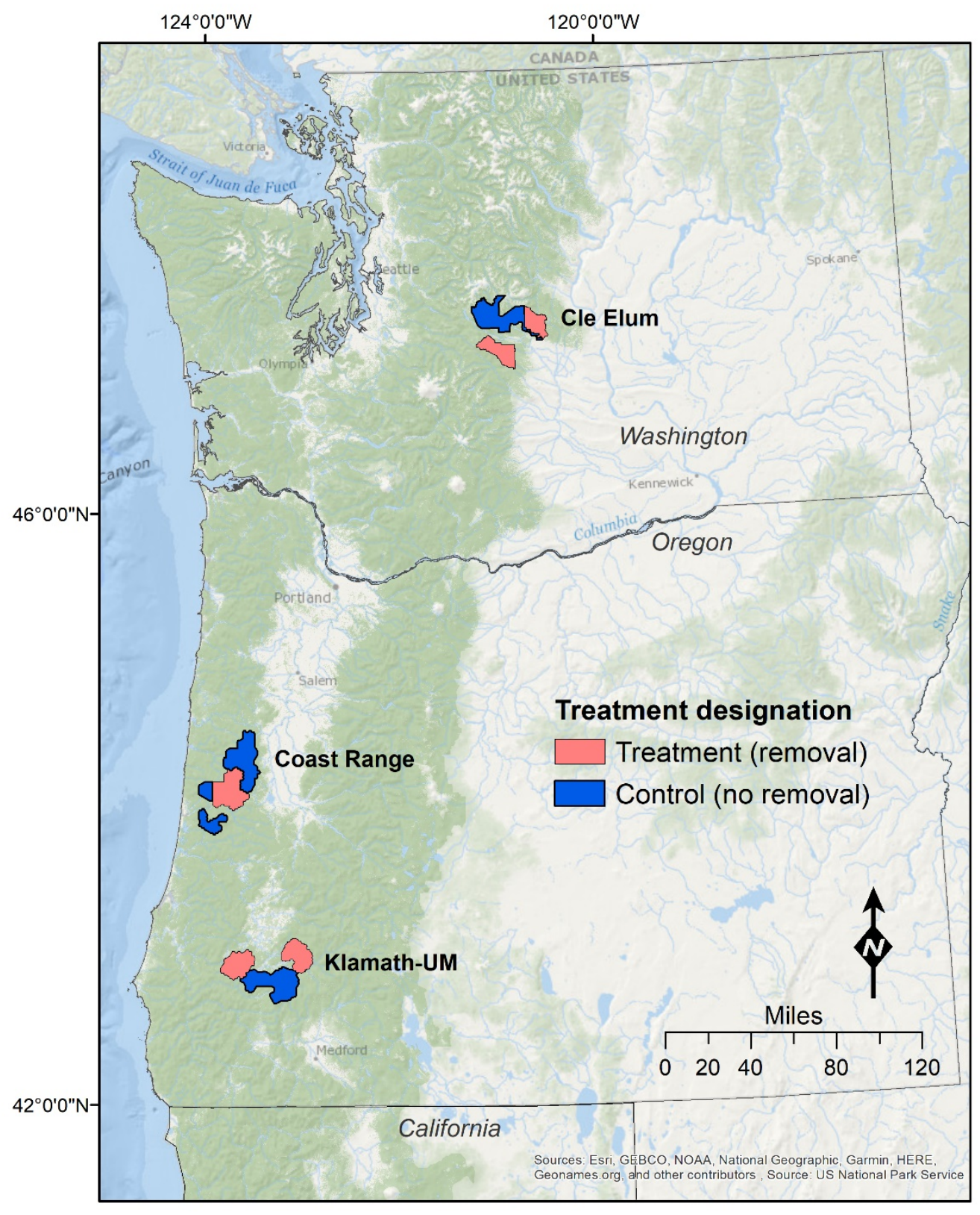

Figure 1. Locations of treatment (barred owls removed) and control (no removal) portions of three study areas in Washington and Oregon used to characterize the effect of barred owl removal on population dynamics of northern spotted owls. 


\section{Methods}

\section{Owl Surveys and Population Monitoring}

We used species-specific surveys to document BACI changes in populations of spotted owls and barred owls. Annual surveys and mark-recapture studies of spotted owls at historically occupied territories were completed as part of a long-term demographic monitoring program (Franklin and others, 1996, Lint and others, 1999; Dugger and others, 2016). Recent summaries of spotted owl population trends, breeding and mate status of detected owls, number of owls banded, inter-territory movements and general age distribution are reported elsewhere (Lesmeister and others, 2020a-c).

We used a standard site-occupancy design described by Wiens and others (2011) to survey barred owls. Mean home-range size for barred owls in the Pacific Northwest ranges from 4-7 square kilometers $\left(\mathrm{km}^{2}\right)$ (Wiens and others, 2014). Using home-range size as a guide, a grid of 5- $\mathrm{km}^{2}$ hexagons was overlaid across each study area. We considered each hexagon grid cell a site and surveyed each site repeatedly over three sampling periods within the breeding season: March 1-May 7, May 8 - July 9, and July 10 - September 10, 2019. Sampling periods reflected approximate transition dates between incubation, nestling, and fledgling-dependency breeding stages of barred owls (Wiens and others, 2011; 2014). During each survey, observers used an amplified megaphone (FoxPro, Lewiston, Pennsylvania; Wildlife Technologies, Manchester, New Hampshire) to broadcast digitally recorded calls of barred owls at two to five call points established in each site. Observers recorded the number and sex of barred owls detected during each survey. A site was considered used by at least one territorial pair of barred owls if (1) both sexes were observed within 400 meters (m) of each other on a single visit or (2) at least one adult was observed with young (Wiens and others, 2011).

\section{Barred Owl Removal}

We used well-established field protocols for the removal and scientific collection of barred owls (Diller and others, 2014, 2016; U.S. Fish and Wildlife Service, 2013). Barred owls detected in treatment areas were removed using 12-gauge shotguns loaded with nontoxic shot. We observed frequent recolonization by barred owls, so we did regular followup visits to detect newly colonizing barred owls and conduct additional removals as needed. We determined sex of barred owls in the field based on vocalizations and morphometric measurements, and later verified those determinations in the lab by examining sex organs. We classified barred owls as either subadults (owls in their 1st or 2nd year) or adults (owl 3 years and older) based on molt and plumage characteristics observed under ultraviolet light (Weidensaul and others, 2011), and by identifying juvenile flight feathers. Barred owls were stored locally at each study area until distributed as scientific specimens to museums and universities (app. 1).

The protocol for removals we used prohibited collection of barred owls with dependent young (U.S. Fish and Wildlife Service, 2013). As a consequence, we completed removals in the nonbreeding season (September-April) or in cases where observers had high confidence in determining reproductive status of individuals (U.S. Fish and Wildlife Service, 2013). Such cases were typically at sites where we documented rapid (within 2-3 weeks) recolonization of new barred owls after removing of the previous occupants in early spring, prior to the estimated mean hatching date for barred owls ( April 15; Wiens and others, 2014). Breeding season removals were generally focused in areas known to be recently occupied by spotted owls. We were unable to complete breeding season removals in the Cle Elum study area during 2016-18 because snow limited access to removal sites in early spring. All barred owl removals were conducted by personnel certified by the U.S. Geological Survey. Field protocols used for 
surveys and lethal removals of barred owls were reviewed and approved by the Institutional Animal Care and Use Committee at Oregon State University and were completed under Federal and State Scientific Collection permits.

\section{Assessing the Initial Effects of Removals}

\section{Barred Owl Occupancy Dynamics}

We used multi-season occupancy models (MacKenzie and others, 2002, 2006) to track annual changes in barred owls on control versus treatment areas and quantify the effectiveness of removals in reducing populations. We focused inferences from the analysis on detections/non-detections of at least one pair of barred owls because territorial pairs have the potential to reproduce and may defend their territories more aggressively than single birds,. Site-specific detection histories were used to estimate the probability (1) of use by at least one pair of barred owls in the year prior to removals (initial occupancy, $\psi_{1}$ ); (2) that used sites become unused (local extinction, $\varepsilon$ ); (3) that unused sites become used (local colonization, $\gamma$ ); and (4) of detecting at least one pair of barred owls given the site was used (p). Actual territory boundaries (defended areas) may overlap more than one hexagon used for surveys, so we interpreted occupancy as the probability of a used territory (defended area) overlapping with a 5$\mathrm{km}^{2}$ survey site (that is, site usage; Kendall and others, 2013; Davis and others, 2018). We retain the term occupancy to maintain standardized terminology used for this modeling approach. At survey sites with year-round removal of non-nesting barred owls $(n=39)$, we considered only surveys within a breeding season that occurred prior to removal of the last barred owl to minimize bias of parameter estimates (Diller and others, 2016).

We used program MARK (White and Burnham, 1999) to determine how removals and time (year) influenced the occupancy dynamics of barred owls. We first examined the effects of treatment level (control versus treatment), year, and visits within years on detection probability. After retaining the best structure for detection, we moved on to model initial occupancy, colonization, and then extinction. We examined evidence for treatment effects on extinction and colonization rates as a group effect, which allowed parameter estimates to vary between sites with and without removals. We compared support for models with and without the effect of barred owl removal included and used information theoretic methods to rank and select among competitive models (Burnham and Anderson, 2002). We calculated model-averaged estimates where appropriate, and evaluated the degree to which 95-percent confidence intervals of regression coefficients $(\beta)$ overlapped zero to supplement evidence of treatment effects.

\section{Spotted Owl Territory Occupancy and Reproduction}

We used long-term (2002 - 2019) monitoring data on spotted owls to summarize estimates of numbers of territorial pairs detected, naïve occupancy (proportion of historical territories surveyed with detections of resident pairs of spotted owls), and reproduction (mean number of young produced per pair and total number of young produced per year). Because detection probabilities of spotted owls are below 1 (Dugger and others, 2016), empirical data presented in this report may underestimate actual numbers or territory occupancy of spotted owls. Analyses that account for imperfect detection in estimates of the effects of barred owl removal on population dynamics of spotted owls are forthcoming. 


\section{Results}

\section{Barred Owl Surveys and Removals}

From 2015 to 2019, we completed 8,004 surveys of barred owls at 765 hexagons (409 control and 356 treatment). By August of 2019, the mean number of individual barred owls detected per hexagon in treatment (removal) areas had decreased by 77 (Cle Elum study area), 44 (Coast Range study area) and 47 (Klamath-UM study area) percent relative to pretreatment estimates (fig. 2). In control areas, the mean number of barred owls detected increased by 14 (Coast Range study area) to 69 (Klamath-UM study area) percent in Oregon, but declined by 19 percent in Washington. We detected 23 times as many barred owls in the Coast Range relative to the other 2 study areas (fig. 2).
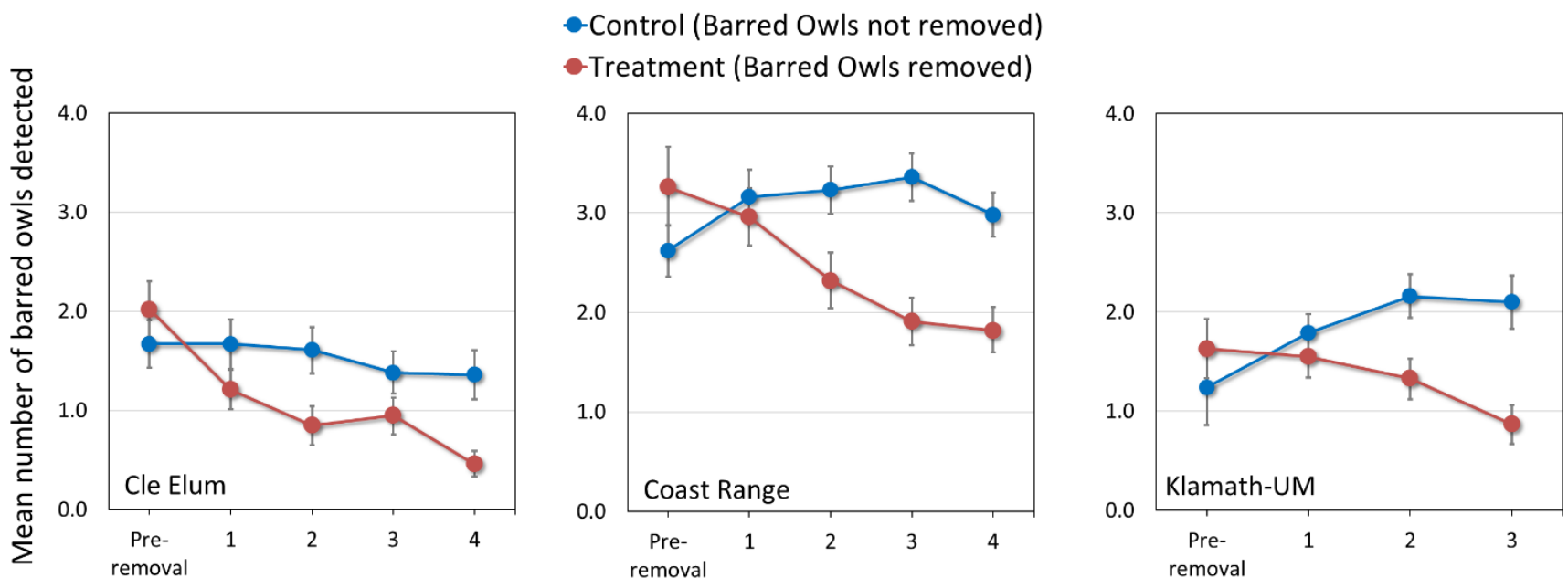

Years of removal effort

Figure 2. Average number of barred owls detected per 5-km² hexagon in control (barred owls not removed) and treatment (barred owls removed) portions of three study areas before and after barred owls were removed in Washington and Oregon, 2015-19. Annual means were calculated as the maximum number of individuals detected per hexagon, divided by the total number of hexagons surveyed. Error bars represent standard error.

Field crews completed 4,384 site visits to remove a total of 2,066 barred owls: 486 in the Cle Elum study area, 1,034 in the Coast Range study area, and 546 in the Klamath-UM study area (fig. 3). The sample included 908 females, 1,107 males, and 51 owls of unknown sex. A minimum of 412 territorial pairs of barred owls were removed. We recovered 2,048 carcasses -18 carcasses could not be recovered because they were either too high in a tree to reach, fell onto areas unsafe for access, or could not be located after a single lethal shot. Forty-two (2.1 percent) barred owls required euthanasia using an Institutional Animal Care and Use Committee -approved penetrating bolt device (Bunny Rancher Inc., Frankfort, Maine). There were no known cases where a nontarget species was injured or mistakenly killed. Carcasses of barred owls were provided as scientific specimens to 28 different institutions for education and research purposes (app. 1). 


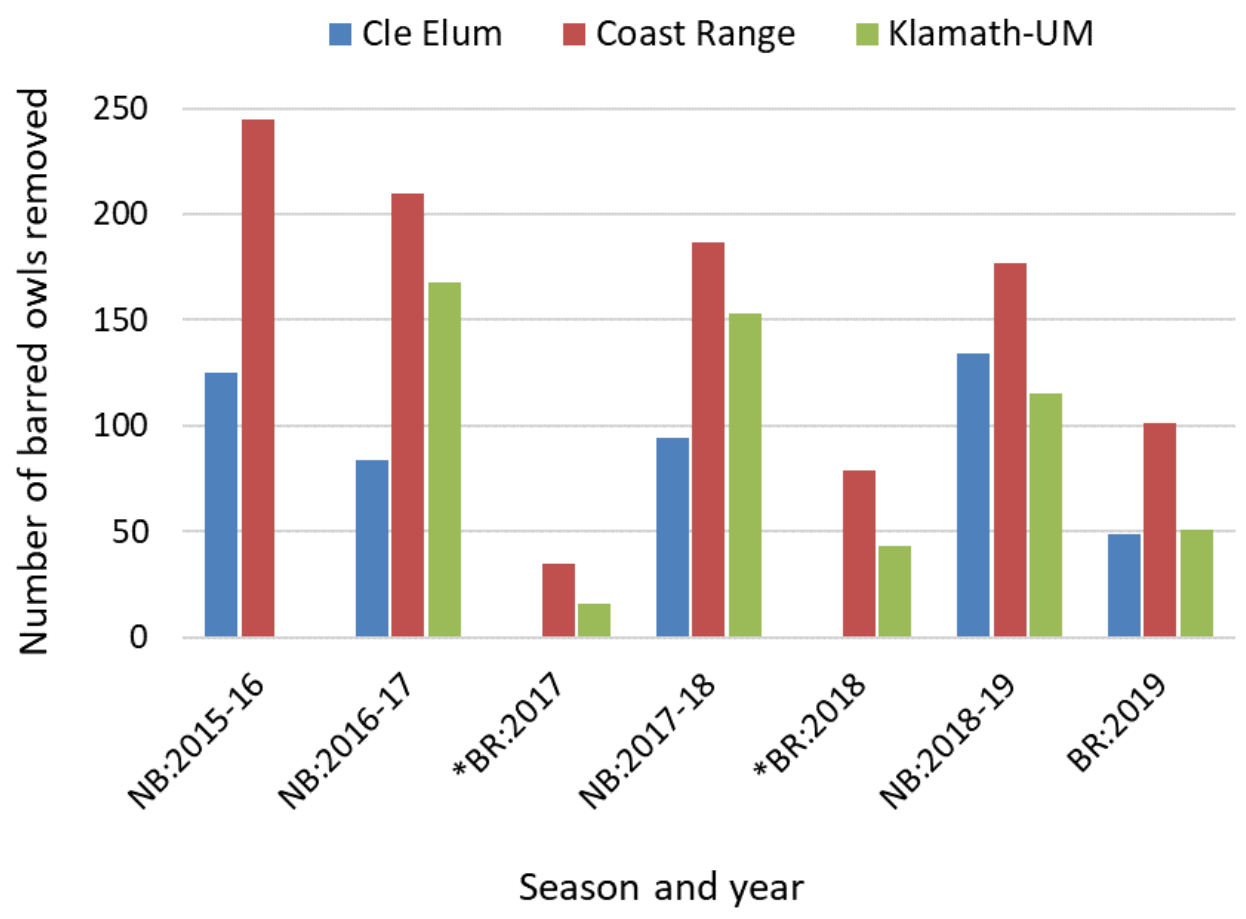

Figure 3. Numbers of barred owls removed by season in three experimental study areas in Washington and Oregon, 2015-19. Nonbreeding (NB) and breeding (BR) seasons were from September 1 to April 15 and April 16 to August 31, respectively. Removals during the breeding season $\left({ }^{*}\right)$ were not conducted in 2016 and were limited to the Coast Range and Klamath-UM study areas in 2017 and 2018.

We observed a high level of spatial variation within and among study areas in numbers of barred owls removed, which we attributed to regional- and site-specific differences in the rate of recolonization following removals (fig. 4, also see Barred Owl Occupancy Dynamics below). The mean number of barred owls removed per $5-\mathrm{km}^{2}$ hexagon during the study period was 4.6 in the Cle Elum study area (range $=0-26$ owls), 10.0 in the Oregon Coast Range study area (range $=0-46$ owls), and 3.8 in the Klamath-UM study area (range $=0-22$ owls).
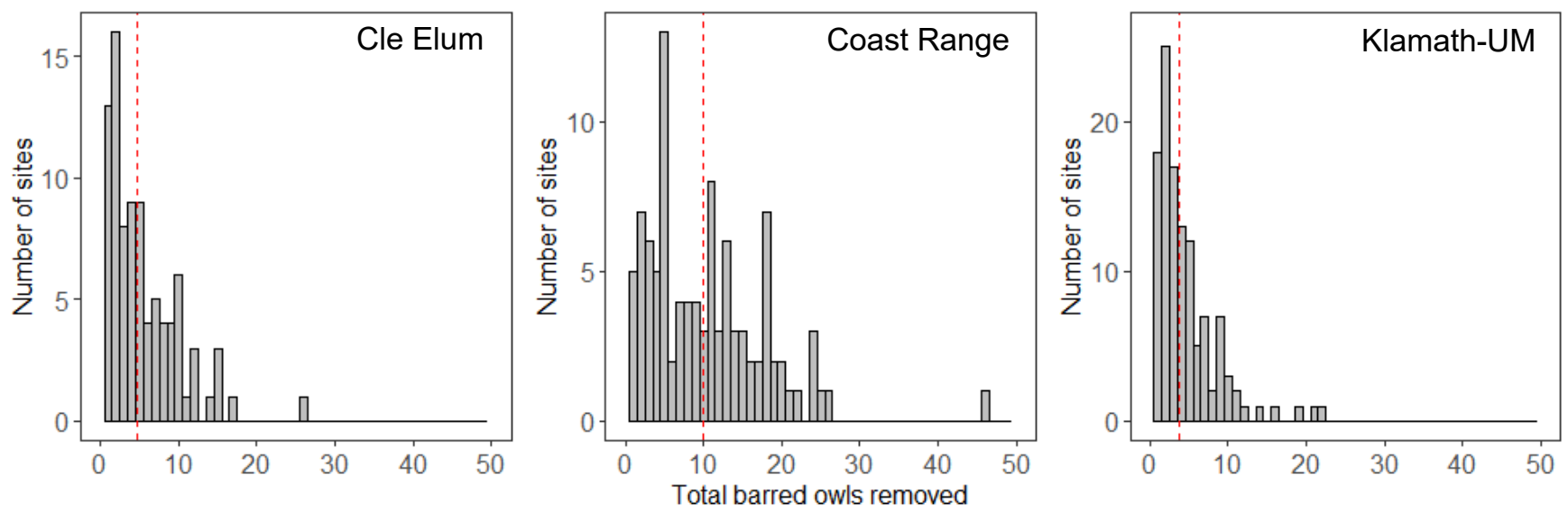

Figure 4. Variation among study areas and sites ( $5 \mathrm{~km}^{2}$ hexagons) in numbers of barred owls removed during 2015-19. The mean number of barred owls removed per site over 3 (Klamath-UM study area) to 4 (Cle Elum and Coast Range study areas) years of removal effort is indicated by a dashed vertical red line. 


\section{Initial Effects of Removals}

\section{Barred Owl Occupancy Dynamics}

Before removals, there was no evidence of differences between control and treatment areas in expected site occupancy of barred owls (fig. 5; app. 2). After removals, expected occupancy of barred owls in treatment areas declined by 13 (Coast Range study area) to 60 (Cle Elum study area) percent relative to pretreatment estimates (table 2). In contrast, expected occupancy in control areas remained relatively constant (Coast Range and Klamath-UM study areas) or was slowly decreasing (Cle Elum study area). The effectiveness of removals in reducing site occupancy, as shown by differences between control and treatment areas in post-removal years, varied substantially among the three study areas (table 2, fig. 5).
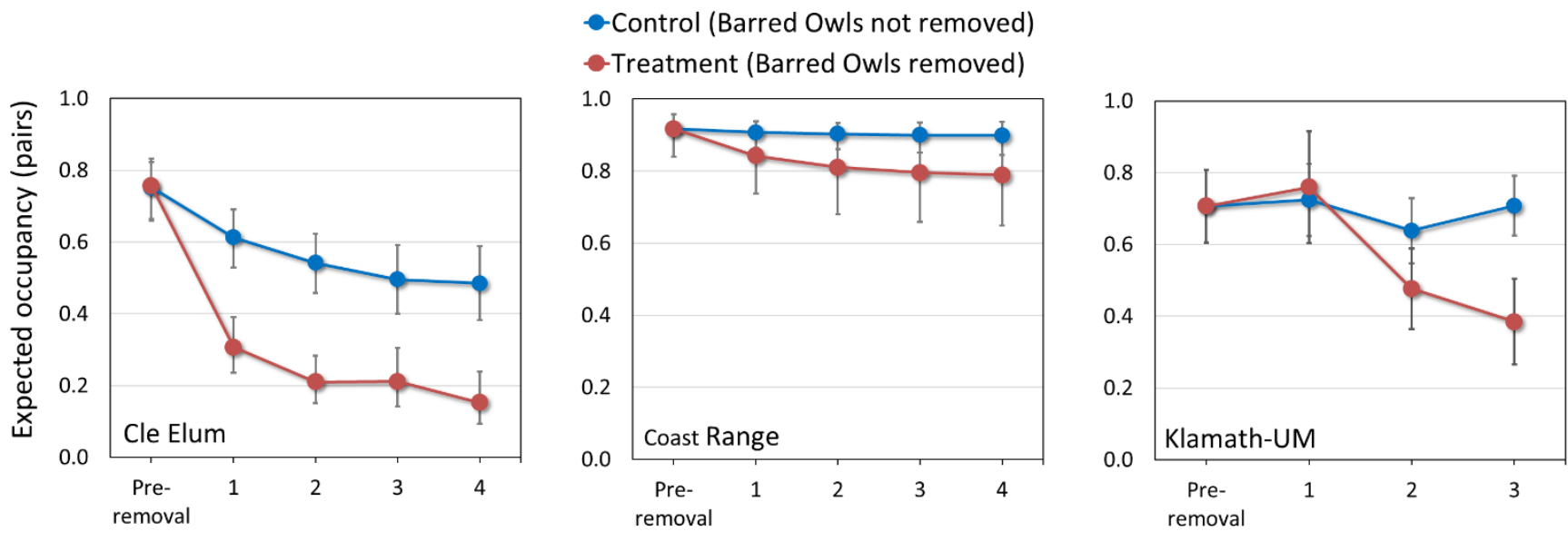

Years of removal effort

Figure 5. Model-averaged estimates of landscape occupancy $(\widehat{\bar{\psi}})$ by territorial pairs of barred owls in control (barred owls not removed) compared to treatment (barred owls removed) portions of three study areas in Washington and Oregon, 2015-19. Error bars are unconditional 95-percent confidence intervals.

There was strong evidence that removals increased local extinction probabilities of barred owls in all three study areas (apps. 2, 3). Models that included the effect of treatment on extinction probability consistently outperformed models without this effect, and 95-percent confidence intervals of associated beta coefficients did not include zero (app. 2). By 2019, extinction rates were 2.7-4.6 times greater in treatment sites relative to controls (app. 3). We found weak evidence of treatment (removal) effects on local colonization of barred owls. Post-removal recolonization rates of barred owls in treated areas were substantially greater in the Coast Range study area $(\hat{\gamma}=0.42, \mathrm{SE}=0.12)$ than in the Cle Elum $(\hat{\gamma}=0.09, \mathrm{SE}=0.05)$ or Klamath-UM study areas $(\hat{\gamma}=0.17, \mathrm{SE}=0.07$; app. 3$)$. The consistently high annual rate of recolonization by new territorial pairs we observed in the Coast Range study area largely compensated for the negative effect of removals on expected site occupancy (table 2; fig. 5). 
Table 2. Model-averaged estimates of expected occupancy $(\widehat{\bar{\psi}})$ by territorial pairs of barred owls, with unconditional standard errors (SE) and lower (LCL) and upper (UCL) confidence limits, before and after removals in three experimental study areas in Washington and Oregon, 2015-19.

$\left[\% \Delta=\right.$ percent change in expected occupancy during the study period $\left(\widehat{\overline{\boldsymbol{\Psi}}}_{\text {pre }}-\hat{\overline{\boldsymbol{\Psi}}}_{2019} \times 100\right) . \hat{\overline{\boldsymbol{\Lambda}}}_{2019}=$ model averaged annual rate of change in occupancy between 2018 and 2019]

\begin{tabular}{|c|c|c|c|c|c|c|c|c|c|c|}
\hline \multirow{2}{*}{ Treatment level } & \multicolumn{10}{|c|}{ Model-averaged estimates } \\
\hline & $\widehat{\overline{\boldsymbol{\Psi}}}_{\text {pre }}$ & SE & $\mathrm{LCL}$ & UCL & $\hat{\bar{\Psi}}_{2019}$ & SE & $\mathrm{LCL}$ & UCL & $\% \Delta$ & $\hat{\bar{\lambda}}_{2019}$ \\
\hline \multicolumn{11}{|c|}{ Cle Elum, Washington } \\
\hline Control & 0.752 & 0.040 & 0.665 & 0.823 & 0.485 & 0.054 & 0.382 & 0.589 & -27 & 1.05 \\
\hline Treatment & 0.757 & 0.044 & 0.660 & 0.833 & 0.153 & 0.037 & 0.094 & 0.239 & -60 & 0.52 \\
\hline \multicolumn{11}{|c|}{ Coast Range, Oregon } \\
\hline Control & 0.917 & 0.029 & 0.840 & 0.959 & 0.899 & 0.023 & 0.844 & 0.936 & -2 & 1.00 \\
\hline Treatment & 0.917 & 0.029 & 0.840 & 0.959 & 0.789 & 0.060 & 0.649 & 0.883 & -13 & 0.99 \\
\hline \multicolumn{11}{|c|}{ Klamath-UM, Oregon } \\
\hline Control & 0.707 & 0.052 & 0.606 & 0.808 & 0.708 & 0.042 & 0.625 & 0.791 & $<1$ & 1.11 \\
\hline Treatment & 0.707 & 0.052 & 0.606 & 0.808 & 0.385 & 0.061 & 0.265 & 0.504 & -32 & 0.81 \\
\hline
\end{tabular}

Spotted Owl Territory Occupancy and Reproduction

Long-term data prior to barred owl removals show sharp declines in annual numbers of resident spotted owls detected in control and treatment areas (fig. 6A). In the year prior to removals (2016 in the Klamath-UM study area, 2015 in the other areas), the total number of pairs of spotted owls detected across all control and treatment areas combined was 30 and 17, respectively (table 3$)^{4}$. After 3-4 years of removal effort, the total number of pairs detected was 5 and 19, respectively. This total represented an 83-percent decrease in numbers of pairs on control areas compared to a 12-percent increase in numbers on treated areas with barred owl removal. Post-removal changes were most pronounced in the Oregon Coast Range study area, where the number of pairs detected in treated areas has doubled during the study yet decreased by 91 percent in control areas (table 3; fig. $6 \mathrm{~A}$ ).

Long-term empirical data show that the annual number of fledgling spotted owls produced in control compared to treatment areas was highly variable among years and study areas (fig. 6B). In 2019, ten (91 percent) of 11 pairs of spotted owls that successfully fledged young were in treatment areas with barred owl removal (table 4). Differences in spotted owl reproduction in control compared to treatment areas were most pronounced in the Klamath-UM study area. All pairs that successfully produced young in 2019 in the Klamath-UM study area were in areas with consistent, year-round barred owl removal effort.

${ }^{4}$ Data on spotted owls are specific to control and treatment portions of each study area, so may vary from estimates reported in these areas by Regional Ecosystem Office (www.fs.fed.us/r6/reo/monitoring/reports/). 
Table 3. Annual estimates of territory occupancy by pairs of northern spotted owls in control (barred owls not removed) and treatment (barred owls removed) portions of three study areas in Washington and Oregon, 2015-18.

[Shading indicates years in which barred owls were removed in treatment areas (four years in Cle Elum and Oregon Coast Range, three years in Klamath-UM]

\begin{tabular}{|c|c|c|c|c|c|c|c|}
\hline \multirow[t]{2}{*}{ Treatment level } & & \multirow{2}{*}{$\begin{array}{c}\text { Historical } \\
\text { territories } \\
\text { surveyed }\end{array}$} & \multicolumn{5}{|c|}{$\begin{array}{l}\text { Number of territories with pairs of spotted owls detected } \\
\text { (proportion of historical territories with pairs in parentheses) }\end{array}$} \\
\hline & & & 2015 & 2016 & 2017 & 2018 & 2019 \\
\hline \multicolumn{8}{|c|}{ Cle Elum, Washington } \\
\hline Control & 32 & & $5(0.16)$ & $2(0.06)$ & $2(0.06)$ & $3(0.09)$ & $1(0.03)$ \\
\hline Treatment & 45 & & $2(0.04)$ & $2(0.04)$ & $2(0.04)$ & $3(0.07)$ & $3(0.07)$ \\
\hline \multicolumn{8}{|c|}{ Coast Range, Oregon } \\
\hline Control & & 58 & $11(0.19)$ & $9(0.16)$ & $6(0.10)$ & $1(0.02)$ & $1(0.02)$ \\
\hline Treatment & & 45 & $3(0.07)$ & $5(0.11)$ & $4(0.09)$ & $6(0.13)$ & $6(0.13)$ \\
\hline \multicolumn{8}{|c|}{ Klamath-UM, Oregon } \\
\hline Control & & 78 & $18(0.23)$ & $14(0.18)$ & $12(0.15)$ & $5(0.06)$ & $3(0.04)$ \\
\hline Treatment & & 84 & $22(0.26)$ & $12(0.14)$ & $13(0.15)$ & $12(0.14)$ & $11(0.13)$ \\
\hline
\end{tabular}

Table 4. Annual estimates of reproduction of northern spotted owls in control (barred owls not removed) versus treatment (barred owls removed) portions of three study areas in Washington and Oregon, 2015-18.

[Shading indicates years in which barred owls were removed in treatment areas (four years in Cle Elum and Oregon Coast Range, three years in Klamath-UM]

\begin{tabular}{|c|c|c|c|c|c|}
\hline \multirow[t]{2}{*}{ Treatment level } & \multicolumn{5}{|c|}{$\begin{array}{l}\text { Number of territories with } \geq \text { one young fledged } \\
\text { (proportion of sites with fledged young in parentheses) }\end{array}$} \\
\hline & 2015 & 2016 & 2017 & 2018 & 2019 \\
\hline \multicolumn{6}{|c|}{ Cle Elum, Washington } \\
\hline Control & $2(0.06)$ & 0 & $2(0.06)$ & 0 & $1(0.03)$ \\
\hline Treatment & $1(0.02)$ & $2(0.04)$ & $1(0.02)$ & 0 & $3(0.07)$ \\
\hline \multicolumn{6}{|c|}{ Coast Range, Oregon } \\
\hline Control & $3(0.05)$ & 0 & $1(0.02)$ & 0 & 0 \\
\hline Treatment & 0 & $1(0.02)$ & $2(0.04)$ & 0 & $1(0.02)$ \\
\hline \multicolumn{6}{|c|}{ Klamath-UM, Oregon } \\
\hline Control & $8(0.10)$ & $1(0.01)$ & $4(0.05)$ & $1(0.01)$ & 0 \\
\hline Treatment & $6(0.07)$ & $1(0.01)$ & $2(0.02)$ & $1(0.01)$ & $6(0.07)$ \\
\hline
\end{tabular}



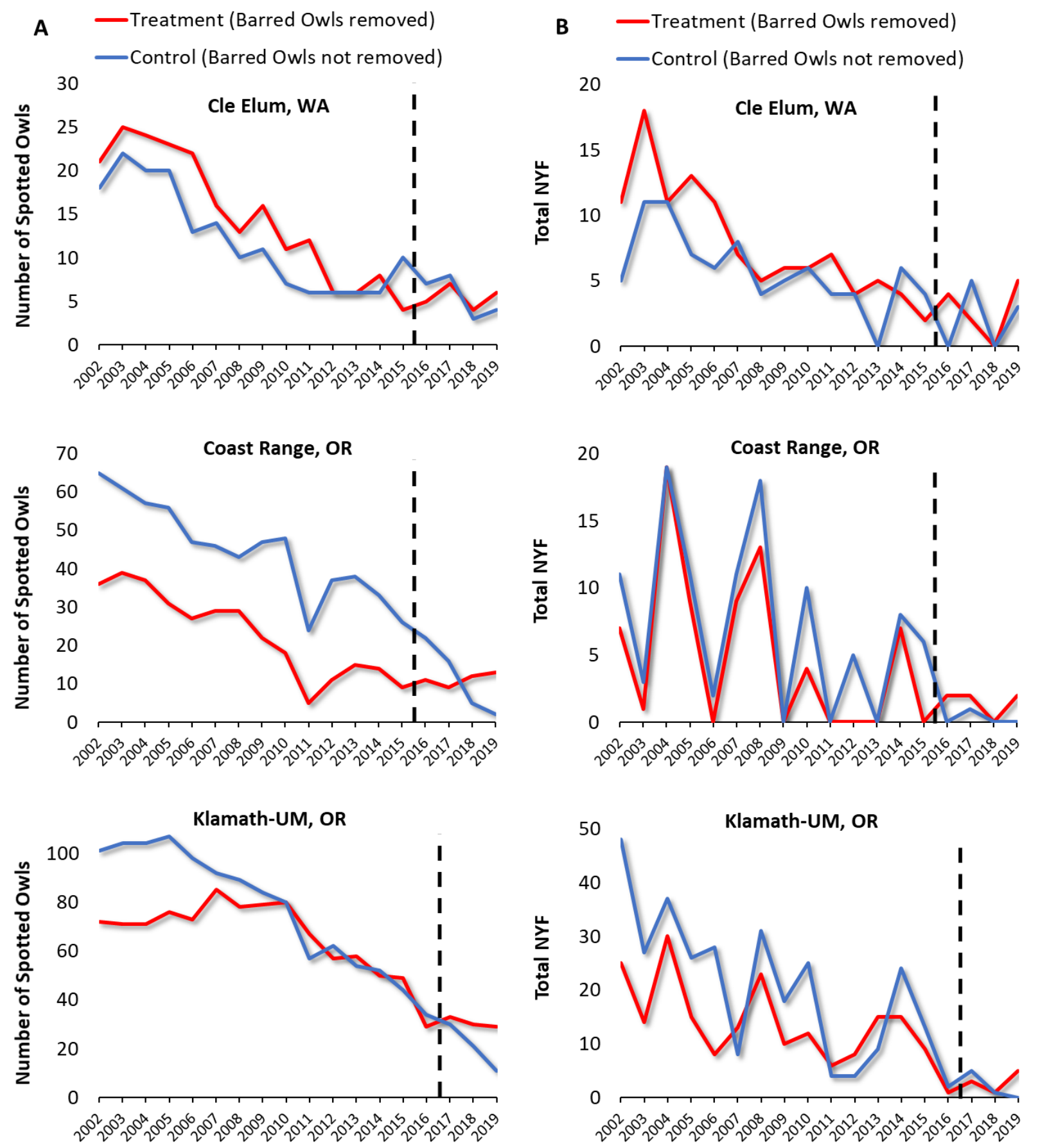

Figure 6. Long-term (2002-19) annual trends in (A) number of individual (resident) northern spotted owls detected, and (B) total number of young fledged (NYF) at control (barred owls not removed) and treatment (barred owls removed) portions of three experimental study areas in Washington and Oregon. Dashed vertical bars indicate the start date of removals in treatment areas. 


\section{Discussion}

Long-term data prior to removals illustrate sharp declines in annual numbers of resident spotted owls detected in control and treatment portions of all three study areas in Oregon and Washington. The declining trend of spotted owls continued in control areas during the study, where an overall 83 percent decline was observed over 4 years in the numbers of territorial pairs detected. In contrast, there was a 12-percent increase in numbers of pairs in treated sites during barred owl removal. These data are preliminary and conclusions from the experiment are pending final and forthcoming analyses of the demographic response of spotted owl to barred owl removal. Moreover, data presented here do not account for imperfect detection of spotted owls during demographic surveys, so may underestimate actual numbers of pairs or individuals, or reproductive output. Nonetheless, the initial results indicate that the numbers of resident spotted owls have been maintained in treated landscapes yet have continued along a declining trajectory in control areas. Posttreatment changes in numbers of spotted owls detected appeared to be the greatest in the Oregon Coast Range study area, where the number of territorial pairs in treated areas has doubled during the study but numbers in control areas have declined by 91 percent.

This initial result was surprising because barred owls in the Oregon Coast Range study area also had the highest recolonization rates following removals, which partially compensated for the effect of removals on landscape occupancy of barred owls.

In 2019, ten of 11 pairs (91 percent) of spotted owls that successfully produced young in our study areas were in areas with barred owl removal. This pattern was largely driven by a discrepancy in reproductive effort of spotted owls in control compared to treatment areas of the Klamath-UM study area (table 3B). In previous studies, a high degree of annual variation in productivity of spotted owls, before and after removal efforts, obscured the ability to quantify how removals affect fecundity of spotted owls (Diller and others, 2016). Low and highly variable reproduction in our study areas in years prior to and during removals (fig. 6B) suggests this may be the case in our study areas as well. Planned analyses of spotted owl reproduction will examine BACI effects of barred owl removal on the mean number of young fledged per territory monitored (for example, table $3 \mathrm{~B}$ ), in addition to fecundity, to better understand how barred owl removal may affect productivity of spotted owls.

Our initial assessment of occupancy dynamics of barred owls indicated that removals effectively reduced populations in treated areas by 13 (Oregon Coast Range study area) to 60 (Cle Elum study area) percent with 3-4 years of removal effort. We also found no evidence that site-occupancy by barred owls varied between control and treatment areas in the year prior to removals. This finding provided confidence that control and treatment areas had similar use by barred owls prior to treatments, and that post-treatment changes could be reliably attributed to removals. In the Oregon study areas, barred owl occupancy remained constant or increased slightly in control areas over time, as would be expected if populations were continuing to expand (or nearing carrying capacity). In contrast, there was a slight reduction observed in barred owl occupancy in the control area of the Cle Elum study area, suggesting that other factors may be influencing populations in these study areas. A consistently high level of spatial variation among sample sites in numbers of barred owls removed (fig. 4, for example) was also observed, which may reflect spatial heterogeneity in habitat quality for colonizing barred owls. Planned analyses will incorporate site-level habitat and disturbance characteristics to more fully characterize how these factors interact with removals to affect colonization or extinction dynamics of barred owls. 


\section{Summary}

During 2015-19, we completed annual demographic surveys of Strix varia (barred owl) and Strix occidentalis caurina (spotted owl) at 765 and 3415 -square kilometer sites, respectively, and a total of 2,066 barred owls were removed from treatment areas. Preliminary results indicate that removals have greatly increased the site-level extinction probability of barred owls and decreased the probability of site use by barred owls across all experimental study areas. In 2019, we detected consistent or increasing numbers of resident spotted owls in treatment areas relative to previous years, with correspondingly sharp decreases in control areas without removals. Collectively, these initial results provide an indicator that removal efforts may be positively influencing territory occupancy, apparent survival, and population trend of spotted owls in the study areas. The numbers of spotted owls remaining in our study areas have reached exceptionally low levels, and annual reproduction during our study period was the lowest recorded over a 28 -year period. Moreover, long-term pre-treatment monitoring data show large inter-annual fluctuations in detections of pairs and individual spotted owls in all the study areas. Final conclusions drawn from the experiment are pending final and forthcoming analyses of the demographic response of spotted owls to barred owl removal.

\section{Acknowledgments}

We thank R. Aragon Perez, K. Austin, K. Bagnall, J. Butch, M. Campbell, B. Gill, S. Hanson, J. Hazen, Q. Huber-Heidorn, M. Hunt, S. Jones, K. Krohn, M. Landever, C. Lebow, D. Merz, M. Nickols, C. Pursley, Z. Pesch, T. Plawman, S. Reffler, L. Richardson, J. Rowe, T. Smith, and N. Wronkiewicz for their field assistance with barred owls. C. McCafferty, S. Sovern, A. Woodrow, and R. Horn provided helpful logistical assistance. Robin Bown provided guidance on funding, permitting, removal protocols, and logistical support. We thank R. Crutchley, K. Fukuda, M. Johnston, T. Kaufmann, N. Kleponis, L. Kufta-Christie, C. Larson, B. Mason, A. Mikkelsen, A. Thomas, K. Wert, A. Price, J. Mowdy, H. Wise, and many others for their field assistance with spotted owls. We thank the many Federal, State, and private landowners who provided permission to access their lands. Two reviewers provided helpful edits and comments that improved the quality of this report. 


\section{References Cited}

Burnham, K.P., and Anderson, D.R., 2002, Model selection and multimodel inference-A practical information-theoretic approach (2d ed.): New York, Springer-Verlag, 488 p.

Davis, A.J., McCreary, R., Psiropoulos, J., Brennan, G., Cox, T., Partin, A., and Pepin, K.M., 2018, Quantifying site-level usage and certainty of absence for an invasive species through occupancy analysis of camera-trap data: Biological Invasions, v. 20, no. 4, p. 877-890. accessed February 19, 2019, at https://doi.org/10.1007/s10530-017-1579-x.

Diller, L.V., Dumbacher, J.P., Bosch, R.P., Bown, R.R., and Gutiérrez, R.J., 2014, Removing barred owls from local areas-Techniques and feasibility: Wildlife Society Bulletin, v. 38, no. 1, p. 211-216, accessed January 1, 2015, at https://doi.org/10.1002/wsb.381.

Diller, L.V., Hamm, K.A., Early, D.A., Lamphear, D.W., Dugger, K.M., Yackulic, C.B., Schwarz, C.J., Carlson, P.C., and McDonald, T.L., 2016, Demographic response of northern spotted owls to barred owl removal: The Journal of Wildlife Management, v. 80, p. 691-707, accessed January 1, 2017, at https://doi.org/10.1002/jwmg.1046.

Dugger, K.M., Forsman, E.D., Franklin, A.B., and others, 2016, The effects of habitat, climate and barred owls on long-term demography of northern spotted owls: The Condor-Ornithological Applications, v. 118, p. 57-116, accessed April 21, 2017, at https://doi.org/10.1650/CONDOR-1524.1.

Franklin, A.B., Anderson, D.R., Forsman, E.D., Burnham, K.P., and Wagner, F.W., 1996, Methods for collecting and analyzing demographic data on the northern spotted owl: Studies in Avian Biology, v. 17 , p. 12-20.

Johnson, D.H., White, G.C., Franklin, A.B., Diller, L.V., Blackburn, I, Pierce, D.J., Olson, G.S., Buchanan, J.B., Thrailkill, J., Woodbridge, B., and Oswald, M., 2008, Study designs for barred owl removal experiments to evaluate potential effects on northern spotted owls: U.S. Fish and Wildlife Service, prepared by Washington Department of Fish and Wildlife, $32 \mathrm{p}$.

Kendall, W.L., Hines, J.E., Nichols, J.D., and Grant, E.H.C., 2013, Relaxing the closure assumption in occupancy models; staggered arrival and departure times: Ecology, v. 94, no. 3, p. 610-617, accessed January 2018, at https://doi.org/10.1890/12-1720.1.

Lesmeister, D.B., McCafferty, C., Booth, H., Lay, M., Padilla, W., Phillips, E., Thomas, A., and Wert, K., 2020a, Demographic characteristics of spotted owls in the Oregon Coast Range, 1990-2019:U.S. Forest Service report, $25 \mathrm{p}$.

Lesmeister, D.B., Horn, R., Crutchley, R., Fliegel, E., Fukuda, K., Kupar, A., Langley, S., Larson, C., and Wise, H., 2020b, Demographic characteristics of northern spotted owls (Strix occidentalis caurina) in the Klamath Mountain Province of Oregon, 1990-2019: U.S. Forest Service and Bureau of Land Management report, $27 \mathrm{p}$.

Lesmeister, D. B., S. Sovern, A. Mikkelsen, and J. Mcleod, 2020c, Demography of spotted owls on the east slope of the Cascade Range, Washington, 1989-2019: U.S. Forest Service and U.S. Department of Fisheries and Wildlife report, $26 \mathrm{p}$.

Lint, J.B., Noon, B.R., Anthony, R.G., Forsman, E.D., Raphael, M.G., Collopy, M., and Starkey, E., 1999, Northern spotted owl effectiveness monitoring plan for the northwest forest plan: U.S. Forest Service, General Technical Report PNW-GTR-440, 43 p. [Also available at https://doi.org/10.2737/PNW-GTR-440.]

MacKenzie, D.I., Nichols, J.D., Lachman, G.B., Droege, S., Royle, J.A., and Langtimm, C.A., 2002, Estimating site occupancy rates when detection probabilities are less than one: Ecology, v. 83, p. 2248-2255, accessed February 15, 2005, at https://doi.org/10.1890/00129658(2002)083[2248:ESORWD]2.0.CO;2. 
MacKenzie, D.I., Nichols, J.D., Royle, J.A., Pollack, K.H., Bailey, L.L., and Hines, J.E., 2006, Occupancy estimation and modeling-Inferring patterns and dynamics of species occurrence: Burlington, Massachusetts, Academic Press, 324 p.

U.S. Fish and Wildlife Service, 2013, Experimental removal of barred owl to benefit threatened northern spotted owls - Final environmental impact statement: U.S. Fish and Wildlife Service, 467 p.

Weidensaul, C.S., Colvin, B.A., Brinker, D.R., and Huy, J.S., 2011, Use of ultraviolet light as an aid in age classification of owls: The Wilson Journal of Ornithology, v. 123, p. 373-377, accessed September 13, 2011, at https://doi.org/10.1676/09-125.1.

White, G.C., and Burnham, K.P., 1999, Program MARK - Survival estimation from populations of marked animals: Bird Study, v. 46, p. S120-S138. [Also available at https://doi.org/10.1080/00063659909477239.]

Wiens, J.D., Anthony, R.G., and Forsman, E.D., 2011, Barred owl occupancy surveys within the range of the northern spotted owl: The Journal of Wildlife Management, v. 75, p. 531-538, accessed May 11, 2011, at https://doi.org/10.1002/jwmg.82.

Wiens, J.D., Anthony, R.G., and Forsman, E.D., 2014, Competitive interactions and resource partitioning between northern spotted owls and barred owls in western Oregon: Wildlife Monographs, v. 185, p. 1-50, accessed January 23, 2014, at https://doi.org/10.1002/wmon.1009.

Wiens, J.D., Dugger, K.M., Dilione, K.E., and Simon, D.C., 2019, Effects of barred owl (Strix varia) removal on population demography of northern spotted owls (Strix occidentalis caurina) in Washington and Oregon, 2015-18: U.S. Geological Survey Open-File Report 2019-1074, 17 p.[Also available at https://doi.org/10.3133/ofr20191074.]

Yackulic, C.B., Bailey, L.L., Dugger, K.M., Davis, R.J., Franklin, A.B., Forsman, E.D., Ackers, S.H., Andrews, L.S., Diller, L.V., Gremel, S.A., Hamm, K.A., Herter, D.R., Higley, J.M., Horn, R.B., McCafferty, C., Reid, J.A., Rockweit, J.T., and Sovern, S.G., 2019, The past and future roles of competition and habitat in the range-wide occupancy dynamics of northern spotted owls: Ecological Applications, v. 29, no. 3, article e01861, 8 p., https://doi.org/10.1002/eap.1861. 
This page intentionally left blank. 


\section{Appendix 1. Disposition of Barred Owl Specimens}

Table 1.1. Disposition of barred owl specimens collected during removal experiments in Washington and Oregon, 2015-19.

\begin{tabular}{|c|c|c|}
\hline Destination & Purpose & $\begin{array}{l}\text { Number of } \\
\text { owls }\end{array}$ \\
\hline Field Museum (Chicago, Illinois) & Museum specimen & 425 \\
\hline University of California, Riverside (Riverside, California) & Museum specimen or research & 79 \\
\hline Oregon State University (Corvallis, Oregon) & Museum specimen or research & 78 \\
\hline Cornell University Museum of Vertebrates (Ithaca, New York) & Museum specimen & 72 \\
\hline University of Arizona (Tucson, Arizona) & Museum specimen or research & 68 \\
\hline University of California, Berkeley (Berkeley, California) & Museum specimen & 67 \\
\hline Western Foundation of Vertebrate Zoology (Camarillo, California) & Museum specimen & 59 \\
\hline Bell Museum at University of Minnesota (St Paul, Minnesota) & Museum specimen & 50 \\
\hline Burke Museum (Seattle, Washington) & Museum specimen & 30 \\
\hline Cleveland Museum of Natural History (Cleveland, Ohio) & Museum specimen & 30 \\
\hline Montezuma Audubon Center (Savannah, New York) & Museum specimen & 30 \\
\hline $\begin{array}{l}\text { Academy of Natural Sciences of Drexel University (Philadelphia, } \\
\text { Pennsylvania) }\end{array}$ & Museum specimen & 25 \\
\hline California Academy of Sciences (San Francisco, California) & $\begin{array}{l}\text { Museum specimen or } \\
\text { taxidermy }\end{array}$ & 24 \\
\hline $\begin{array}{l}\text { Moore Laboratory of Zoology at Occidental College (Los Angeles, } \\
\text { California) }\end{array}$ & Museum specimen & 20 \\
\hline Finger Lakes Community College (Canandaigua, New York) & $\begin{array}{l}\text { Classroom education or } \\
\text { research }\end{array}$ & 19 \\
\hline Florida Museum of Natural History (Gainesville, Florida) & Museum specimen & 19 \\
\hline $\begin{array}{l}\text { Natural History Museum of Los Angeles County (Los Angeles, } \\
\text { California) }\end{array}$ & Museum specimen & 19 \\
\hline $\begin{array}{l}\text { University of Colorado Museum of Natural History (Boulder, } \\
\text { Colorado) }\end{array}$ & Museum specimen & 19 \\
\hline The Smithsonian Institution (Washington D.C.) & Museum specimen & 17 \\
\hline University of Wyoming Museum of Vertebrates (Laramie, Wyoming) & Museum specimen & 15 \\
\hline $\begin{array}{l}\text { Peabody Museum of Natural History at Yale University (New Haven, } \\
\text { Connecticut) }\end{array}$ & Museum specimen & 12 \\
\hline $\begin{array}{l}\text { State University of New York College at Cortland [SUNY Cortland] } \\
\text { (Cortland, New York) }\end{array}$ & Classroom education & 11 \\
\hline Liberty Wildlife Non-Eagle Feather Repository (Phoenix, Arizona) & can repository & 10 \\
\hline $\begin{array}{l}\text { Museum of Comparative Zoology at Harvard University (Cambridge, } \\
\text { Massachusetts) }\end{array}$ & Museum specimen & 9 \\
\hline $\begin{array}{l}\text { Kansas University Biodiversity Institute \& Natural History Museum } \\
\text { (Lawrence, Kansas) }\end{array}$ & Museum specimen & 9 \\
\hline $\begin{array}{l}\text { U.S. Geological Survey Forest and Rangeland Ecosystem Science } \\
\text { Center Snake River Field Station (Boise, Idaho) }\end{array}$ & Scientific research & 3 \\
\hline Oregon Department of Forestry (Tillamook, Oregon) & Taxidermy display & 1 \\
\hline High Desert Museum (Bend, Oregon) & Live capture; educational bird & 1 \\
\hline Total barred owls provided & & 1,221 \\
\hline
\end{tabular}




\section{Appendix 2. Multi-Season Occupancy Models Used to Characterize Occupancy Dynamics of Barred Owls}

Table 2.1. Ranking and structure of multi-season occupancy models used to characterize the effects of removals on barred owls in three study areas in Washington and Oregon, 2015-19.

[Model parameter structure and the estimated direction of treatment (removal) effects are shown for all competitive models $(\triangle \mathrm{AICc} \leq 2.5)$ for each individual study area. Bold denotes beta coefficients with 95-percent confidence intervals that did not overlap zero. $\widehat{\overline{\boldsymbol{\Psi}}}_{\text {pre }}$, probability of occupancy in the year before removals began (initial occupancy); $\hat{\varepsilon}$, the probability that a previously used site was not used in the subsequent year (extinction); $\hat{\gamma}$, the probability that a previously unused site was used in the subsequent year (colonization); $\hat{p}$, the probability of detection; trt, treatment; Time effects were modeled as constant (.) or varying with survey period (survey), year, or a before-after indicator of when removals began on treatment areas (trtBA). AICc $=$ Akaike's Information Criterion for small sample size, $\triangle \mathrm{AICc}=$ difference between the AICc value of each model and the lowest AICc model, $\mathrm{K}=$ the number of model parameters, and deviance was the difference in $-2[\log ($ Likelihood $)]$ of the current model and $-2[\log ($ Likelihood $)]$ of the fully saturated model.]

\begin{tabular}{|c|c|c|c|c|c|c|c|c|}
\hline \multirow{2}{*}{$\begin{array}{l}\text { Occupancy } \\
\text { model }\end{array}$} & \multicolumn{4}{|c|}{ Model parameter } & \multicolumn{4}{|c|}{ Model selection criteria } \\
\hline & $\widehat{\overline{\bar{\psi}}}_{\text {pre }}$ & $\widehat{\varepsilon}$ & $\hat{\gamma}$ & $\widehat{\boldsymbol{p}}$ & $\triangle \mathrm{AICC}$ & wi & $\mathrm{K}$ & Deviance \\
\hline \multicolumn{9}{|c|}{ Cle Elum, Washington } \\
\hline 1 & . & $\operatorname{trt}(+)$ & $\operatorname{trt}(-) \times y r$ & survey, trt (-) & 0.00 & 0.30 & 15 & 165.5 \\
\hline 2 & . & $\operatorname{trt}(+)$ & . & survey, $\operatorname{trt}(-)$ & 0.47 & 0.24 & 8 & 180.3 \\
\hline 3 & . & $\operatorname{trt}(+)$ & $\mathrm{yr}$ & survey, $\operatorname{trt}(-)$ & 0.96 & 0.18 & 11 & 174.7 \\
\hline 4 & . & $\operatorname{trt}(+)$ & $\operatorname{trt}(-)$ & survey, $\operatorname{trt}(-)$ & 2.21 & 0.10 & 9 & 180.0 \\
\hline \multicolumn{9}{|c|}{ Coast Range, Oregon } \\
\hline 1 & . & $\operatorname{trt}(+)$ & . & yr, survey, trtBA (-) & 0.00 & 0.63 & 24 & 1040.0 \\
\hline 2 & . & $\operatorname{trt}(+)$ & $\operatorname{trt}(+)$ & yr, survey, trtBA (-) & 1.41 & 0.31 & 25 & 1039.3 \\
\hline \multicolumn{9}{|c|}{ Klamath-UM, Oregon } \\
\hline 1 & . & $\operatorname{trt}(+), y r$ & . & $\mathrm{yr} \times$ survey & 0.00 & 0.40 & 19 & -82.1 \\
\hline 2 & . & $\operatorname{trt}(+), \mathrm{yr}$ & $\mathrm{yr}$ & $\mathrm{yr} \times$ survey & 0.50 & 0.31 & 21 & -85.8 \\
\hline 3 & . & $\operatorname{trt}(+), y r$ & $\operatorname{trt}(-)$ & $\mathrm{yr} \times$ survey & 2.04 & 0.14 & 20 & -82.2 \\
\hline
\end{tabular}




\section{Appendix 3. Post-Removal Extinction and Colonization Rates of Barred Owls}

Table 3.1. Estimated local extinction and colonization rates of barred owls following removal on treatment portions of three study areas in Oregon and Washington, 2018-19.

\begin{tabular}{|c|c|c|c|c|}
\hline \multirow[t]{2}{*}{$\begin{array}{c}\text { Study area and treatment } \\
\text { level }\end{array}$} & \multirow[t]{2}{*}{ Estimate 2018-19 } & \multirow[t]{2}{*}{$\begin{array}{l}\text { Standard } \\
\text { error }\end{array}$} & \multicolumn{2}{|c|}{$\begin{array}{l}\text { Lower (LCL) and upper } \\
\text { (UCL) 95-percent } \\
\text { confidence limits }\end{array}$} \\
\hline & & & $\mathrm{LCL}$ & UCL \\
\hline \multicolumn{5}{|c|}{ Local extinction $(\hat{\bar{\varepsilon}})$} \\
\hline \multicolumn{5}{|l|}{ Cle Elum, Washington } \\
\hline Control & 0.192 & 0.048 & 0.115 & 0.303 \\
\hline Treatment & 0.613 & 0.057 & 0.498 & 0.717 \\
\hline \multicolumn{5}{|l|}{ Coast Range, Oregon } \\
\hline Control & 0.044 & 0.013 & 0.025 & 0.077 \\
\hline Treatment & 0.118 & 0.049 & 0.050 & 0.253 \\
\hline \multicolumn{5}{|l|}{ Klamath-UM, Oregon } \\
\hline Control & 0.002 & 0.017 & 0.000 & 0.036 \\
\hline Treatment & 0.398 & 0.109 & 0.213 & 0.618 \\
\hline \multicolumn{5}{|c|}{ Local colonization $(\hat{\bar{\gamma}})$} \\
\hline \multicolumn{5}{|l|}{ Cle Elum, Washington } \\
\hline Control & 0.166 & 0.069 & 0.070 & 0.347 \\
\hline Treatment & 0.089 & 0.047 & 0.031 & 0.233 \\
\hline \multicolumn{5}{|l|}{ Coast Range, Oregon } \\
\hline Control & 0.382 & 0.084 & 0.235 & 0.554 \\
\hline Treatment & 0.424 & 0.118 & 0.222 & 0.655 \\
\hline \multicolumn{5}{|l|}{ Klamath-UM, Oregon } \\
\hline Control & 0.175 & 0.070 & 0.076 & 0.353 \\
\hline Treatment & 0.173 & 0.069 & 0.075 & 0.351 \\
\hline
\end{tabular}



Publishing support provided by the U.S. Geological Survey Science Publishing Network, Tacoma Publishing Service Center

For more information concerning the research in this report, contact the Director, Forest and Rangeland Ecosystem

Science Center U.S. Geological Survey

777 NW 9th St., Suite 400

Corvallis, Oregon 97330

https://www.usgs.gov/centers/fresc/ 
ํㅡㄹ

웋

禀

क्व

음

옥

立

욜

흘

을

음

물

음

들

果

훙

$\stackrel{8}{8}$

क

今

음

蛋

함

귱

!

옹

웅 